\title{
Effect-site concentration of remifentanil for preventing cough during emergence in elderly patients undergoing nasal surgery: a comparison with adult patients
}

This article was published in the following Dove Press journal:

Clinical Interventions in Aging

12 September 2016

Number of times this article has been viewed

\author{
Ji Young Yoo' \\ Jong Yeop Kim' \\ Hyun Jeong Kwak ${ }^{2}$ \\ Dong Chul Lee ${ }^{2}$ \\ Go Wun Kim' \\ Sook Young Lee' \\ Yun Jeong Chae' \\ 'Department of Anaesthesiology and \\ Pain Medicine, Ajou University School \\ of Medicine, Suwon, ${ }^{2}$ Department of \\ Anaesthesiology and Pain Medicine, \\ Gachon University, Gil Medical \\ Center, Incheon, Korea
}

Correspondence: Yun Jeong Chae Department of Anaesthesiology and Pain Medicine, Ajou University School of Medicine, 164, Worldcup-ro, Yeongtong-gu, Suwon, 16499, Korea $\mathrm{Tel}+82312195576$

Fax +82 31 2195579

Email yjchae06@hotmail.com
Purpose: Prevention of cough during emergence after nasal surgery is important for avoiding surgical site bleeding. We investigated the remifentanil effect-site concentration in 50\% (EC50) of the elderly patients undergoing nasal surgery for smooth emergence without cough and compared it with that of adult patients.

Methods: Twenty-two elderly (aged 65-80 years) and 25 adult patients (aged 20-60 years) with an American Society of Anesthesiologists physical status I/II undergoing nasal surgery were enrolled. Anesthesia was maintained with sevoflurane and remifentanil. Remifentanil EC50 and EC95 for preventing cough were determined using the modified Dixon's up-and-down method and isotonic regression with bootstrapping approach. Recovery profiles were also recorded.

Results: With Dixon's up-and-down method, the EC50 of remifentanil in elderly patients $(2.40 \pm 0.25 \mathrm{ng} / \mathrm{mL})$ was not significantly different from that of adults $(2.33 \pm 0.30 \mathrm{ng} / \mathrm{mL})$ $(P=0.687)$. With isotonic regression, the EC95 of remifentanil in elderly patients $(3.32$ [95\% confidence interval: $3.06-3.38 \mathrm{ng} / \mathrm{mL}$ ) was not significantly different from that of adults (3.30 [95\% confidence interval: $2.96-3.37] \mathrm{ng} / \mathrm{mL})$. However, eye opening time $(14.1 \pm 3.8 \mathrm{vs}$ $12.0 \pm 2.9$ seconds), extubation time $(17.2 \pm 4.1$ vs $14.0 \pm 3.0$ seconds), and postanesthesia care unit duration ( $44.5 \pm 7.6$ vs $38.7 \pm 3.4$ minutes) in elderly patients were significantly longer than those in adults $(P<0.05)$.

Conclusion: Remifentanil EC50 for preventing cough after nasal surgery with sevoflurane anesthesia did not differ between elderly and adult patients. However, delayed awakening and respiratory adverse events may warrant attention in elderly patients.

Keywords: sevoflurane, cough, remifentanil, elderly, extubation

\section{Introduction}

Cough suppression during emergence and tracheal extubation after general anesthesia has become an important issue in patient safety. Cough due to mechanical irritation of the endotracheal tube and cuff can be accompanied by various adverse effects such as laryngospasm, hypertension, tachycardia, arrhythmia, and an increase in intracranial, intraocular, or intra-abdominal pressure. ${ }^{1}$ Consequently, this can lead to myocardial ischemia, disruption of wound, and bleeding at the surgical site. Alongside medical development, an increasing number of elderly patients undergo surgery and exhibit a greater prevalence of cardiovascular disease than younger patients. ${ }^{2,3}$ Therefore, the application of agents for cough suppression during emergence should be investigated further. 
Remifentanil is a selective $\mu$-receptor opioid agonist with a very rapid onset time. Its extrahepatic metabolism by nonspecific esterase results in rapid clearance. ${ }^{4,5}$ Maintenance of remifentanil infusion during emergence has been reported to be an effective method for reducing cough and cardiovascular change without delay of recovery. ${ }^{6,7}$ In previous studies, the effective effect-site concentration for $95 \%$ of adults (EC95) for preventing cough has been shown to vary according to anesthetic agent, type of surgery, and patient sex, and is ranging from 2.14 to $2.94 \mathrm{ng} / \mathrm{mL} .{ }^{8-10}$

The aging process may alter not only the pharmacokinetics and pharmacodynamics, ${ }^{11,12}$ resulting in potentially variable responses to anesthetic drugs (likely increase in sensitivity), but also cough reflex. ${ }^{13}$ The hypothesis of this study is that altered pharmacokinetics and cough sensitivity in elderly patients may require the titration of remifentanil target controlled infusion (TCI) for cough suppression during emergence. To the best of our knowledge, no studies to date have confirmed the effect of remifentanil TCI on cough suppression in the elderly. Therefore, the purpose of this study is to determine the effect-site concentration of remifentanil in 50\% (EC50) of elderly patients undergoing nasal surgery for cough suppression during emergence after balanced anesthesia with sevoflurane and remifentanil. In addition, we have compared the difference in effect-site concentration of remifentanil and recovery profiles between elderly and adult patients.

\section{Patients and methods}

\section{Patients}

Approval was obtained from the Institutional Review Board of Ajou University Hospital (Suwon, Korea), and the study was registered with ClinicalTrials.gov (NCT No: 02334046). All patients provided informed written consent. Twenty-two elderly patients (aged 65-80 years) and 25 adult patients (aged 20-60 years) with an American Society of Anesthesiologists physical status I or II undergoing nasal surgery (endoscopic sinus surgery or septoplasty) were enrolled in this study. The following patients were excluded from the study: those with predicted difficult airway, body mass index $>30 \mathrm{~kg} / \mathrm{m}^{2}$, history of obstructive sleep apnea, chronic respiratory disease or coughing, current smokers, and angiotensin-converting enzyme inhibitor users.

\section{Anesthesia}

Patients were not administered with any premedication. Upon arrival in the operating theater, all patients were monitored via electrocardiography, pulse oximetry, automated noninvasive blood pressure measurement, and bispectral index (BIS) using the BIS ${ }^{\text {TM }}$ Quatro Sensor (Covidien, Boulder, CO, USA) applied to the forehead of each patient. After preoxygenation with $100 \%$ oxygen for 1 minute, anesthesia was induced with a bolus injection of $1.5-2.0 \mathrm{mg} / \mathrm{kg}$ propofol and $2.0-3.0 \mathrm{ng} / \mathrm{mL}$ effect-site concentration of remifentanil via a TCI system (Orchestra ${ }^{\circledR}$, Fresenius Vial, France) using Minto's model. ${ }^{14}$ After loss of consciousness, $0.6 \mathrm{mg} / \mathrm{kg}$ rocuronium was injected and then intubation was performed with a cuffed endotracheal tube (internal diameter $7.5 \mathrm{~mm}$ for males and $7.0 \mathrm{~mm}$ for females). The intracuff pressure was adjusted to 20-25 mmHg using a pressure gauge (Hi-Lo Hand Pressure Gauge, VBM Medizintechnik, GmbH, Germany). Anesthesia was maintained with 1.5-2.5 vol\% sevoflurane and $2.0-4.0 \mathrm{ng} / \mathrm{mL}$ of remifentanil to target a BIS between 40 and 60 , and a mean blood pressure and heart rate within $20 \%$ of baseline values. Mechanical ventilation was adjusted to maintain an end-tidal $\mathrm{CO}_{2}$ between 35 and $40 \mathrm{mmHg}$ using 0.5 fraction of inspired oxygen. Corticosteroids which could affect the results were not administered during surgery. Approximately 15 minutes before the end of surgery, sevoflurane was adjusted to $1-1.2 \mathrm{vol} \%$ to achieve a BIS of $\sim 60$, and remifentanil was set at the predetermined effect-site concentration for obtaining equilibrium between plasma and effect-site at the time of surgery completion. After surgery, sevoflurane was discontinued and $0.004 \mathrm{mg} / \mathrm{kg}$ glycopyrrolate and $0.02 \mathrm{mg} / \mathrm{kg}$ neostigmine were injected for reversal of residual muscle relaxation after achieving a train-of-four ratio of 0.9 . Oropharyngeal suction was gently performed before injection of reversal agents. Mechanical ventilation was switched to manual ventilation to maintain an end-tidal $\mathrm{CO}_{2}$ between 40 and $45 \mathrm{mmHg}$. Extubation was performed when patients were able to open their eyes on command and following the recovery of adequate spontaneous ventilation. Immediately after extubation, remifentanil infusion was stopped and $100 \%$ oxygen was administered via a face mask for 5 minutes. The presence of cough was recorded by the investigator who was unaware of the concentration of remifentanil. After confirmation of consciousness and adequate respiration, patients were transferred to the postanesthetic care unit (PACU). In the PACU, fentanyl $1 \mu \mathrm{g} / \mathrm{kg}$ was administered when the pain score exceeded 5 points on the numerical rating scale. Patients were discharged from the PACU when Aldrete score was $\geq 9 .{ }^{15}$

\section{Determination of effect-site concentration and recovery profiles}

The Dixon's up-and-down method was used to determine the effect-site concentration of remifentanil for cough suppression during the emergence period (in the presence of 
endotracheal tube, during tracheal extubation, and 5 minutes after extubation). ${ }^{16}$ If coughing occurred during the emergence period, it was considered a failure of cough suppression. The initial effect-site concentration of remifentanil was $1.8 \mathrm{ng} / \mathrm{mL}$. In the next patient, the effect-site concentration of remifentanil was determined by the success or failure of cough suppression of the previous patient. If cough suppression was a success, then the effect-site concentration of remifentanil was reduced by $0.4 \mathrm{ng} / \mathrm{mL}$, while in case of failure it was increased by $0.4 \mathrm{ng} / \mathrm{mL}$. The remifentanil EC50 of patients, which enabled successful cough suppression, was determined by calculating the mean of the midpoint effect-site concentration of all independent pairs after six crossover points were obtained (ie, success to failure).

Hemodynamic data and respiratory profiles were recorded before anesthesia induction (baseline), at the end of surgery, at eye opening, immediately after extubation, and 5 minutes after extubation. The eye opening and extubation times were also measured and events of hypoventilation $<8$ breaths $/ \mathrm{min}$ or oxygen saturation $\left(\mathrm{SaO}_{2}\right)$ below $95 \%$ were recorded.

\section{Statistical analysis}

The sample size was decided based on prior literature about the modified Dixon's up-and-down method. To minimize the inaccuracy of the individual study, more than the minimum six crossover points are required in this method. ${ }^{17}$
Statistical analyses were performed using the Statistical Package for Social Sciences (version 20.0 for Windows; IBM Corporation, Armonk, NY, USA) and R for Windows (version 3.0.1; The R Foundation for Statistical Computing; https://www.r-project.org). The EC50 calculated from the modified Dixon's up-and-down method was compared between the two patient groups using a $t$-test. For backup analysis, the data were analyzed using the isotonic regression method to estimate EC50 and EC95 along with 95\% confidence intervals (CIs). The isotonic regression is a variant of restricted least squares regression to constrain the point estimates to either increase or decrease monotonically, which has favorable statistical properties. ${ }^{18}$ The CI was estimated using the bootstrapping approach. ${ }^{18}$ All other variables were compared between groups using an independent $t$-test, chisquare test, Fisher's exact test, or Mann-Whitney $U$ statistic, where appropriate. Hemodynamic data were analyzed with repeated measures of analysis of variance. Data were presented as the mean \pm standard deviation or the number of patients. Statistical significance was accepted when the $P$-value was $<0.05$.

\section{Results}

In total, 47 patients completed the study (Figure 1). The elderly patient group comprised 22 patients with a mean age of 69 (range: $65-80$ years) and the adult patient group comprised 25 patients with a mean age of 35 (range: $20-60$ years).

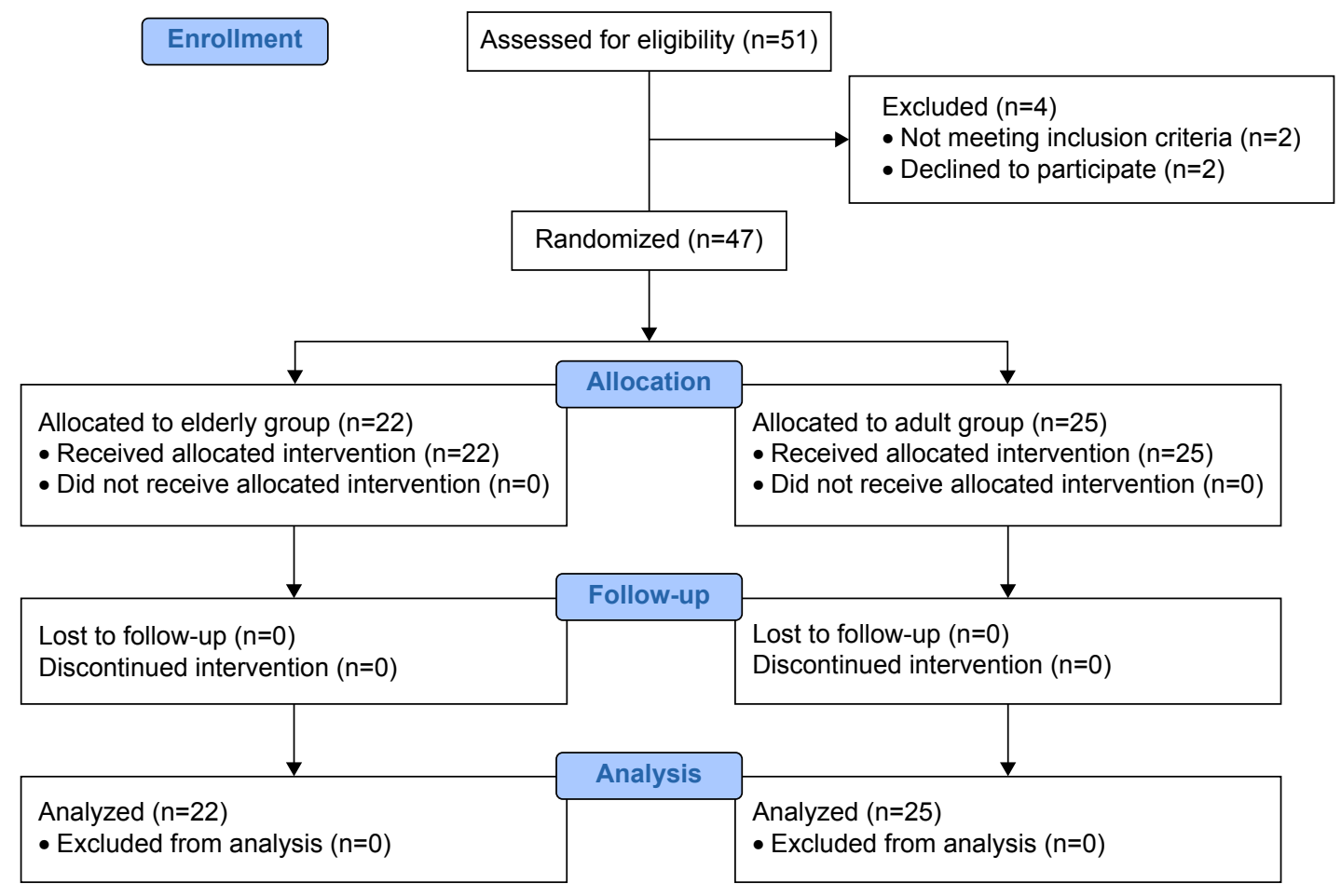

Figure I Consort flow diagram. 
Table I Patient characteristics

\begin{tabular}{|c|c|c|c|c|}
\hline \multirow[t]{2}{*}{ Variables } & \multicolumn{2}{|c|}{$\begin{array}{l}\text { Elderly patients } \\
(\mathrm{n}=22)\end{array}$} & \multicolumn{2}{|c|}{$\begin{array}{l}\text { Adult patients } \\
(n=25)\end{array}$} \\
\hline & Success & Failure & Success & Failure \\
\hline Sex ( & $5 / 5$ & $10 / 2$ & $9 / 3$ & $10 / 3$ \\
\hline Age (years) & $67.9 \pm 2.8$ & $70.5 \pm 4.2$ & $37.4 \pm 12.9$ & $32.8 \pm 11.0$ \\
\hline Weight (kg) & $66.0 \pm 10.0$ & $64.4 \pm 10.3$ & $67.8 \pm 13.5$ & $72.1 \pm 11.2$ \\
\hline Height (cm) & $160.4 \pm 9.8$ & $165.8 \pm 8.2$ & $170.7 \pm 7.5$ & $|7| .6 \pm 8.4$ \\
\hline ASA physical status (I/II) & $2 / 8$ & $3 / 9$ & $11 / 1$ & $11 / 2$ \\
\hline
\end{tabular}

Notes: Values are expressed as mean \pm standard deviation or number. ASA I is defined as a normal healthy patient; ASA II is defined as a patient with mild systemic disease.

Abbreviation: ASA, American Society of Anesthesiologists.

Patient characteristics are presented in Table 1. There were significantly more patients in the elderly groups with an American Society of Anesthesiologists physical status of II than in the adult group $(P<0.001)$. During mask ventilation and intubation, there was no unpredicted difficult airway.

The sequence of dose-response data for each patient is shown in Figure 2. Using the modified Dixon's up-and-down method, the EC50 of remifentanil was not significantly different between the elderly and adult groups $(2.40 \pm 0.25$ vs $2.33 \pm 0.30 \mathrm{ng} / \mathrm{mL}$, respectively, $P=0.687)$. With isotonic regression and the bootstrapping approach, the EC50 of remifentanil was similar between the elderly and adult groups $(2.50$ [95\% CI: $2.38-2.75] \mathrm{ng} / \mathrm{mL}$ and 2.52 [95\% CI: 2.29-2.78] ng/mL, respectively). The EC95 of remifentanil was also similar between the elderly and adult groups (3.32 [95\% CI: 3.06-3.38] ng/mL and 3.30 [95\% CI: 2.96-3.37] $\mathrm{ng} / \mathrm{mL}$, respectively).

Recovery profiles are presented in Table 2. While the number of patients presenting cough and the effectsite concentration of remifentanil for cough suppression

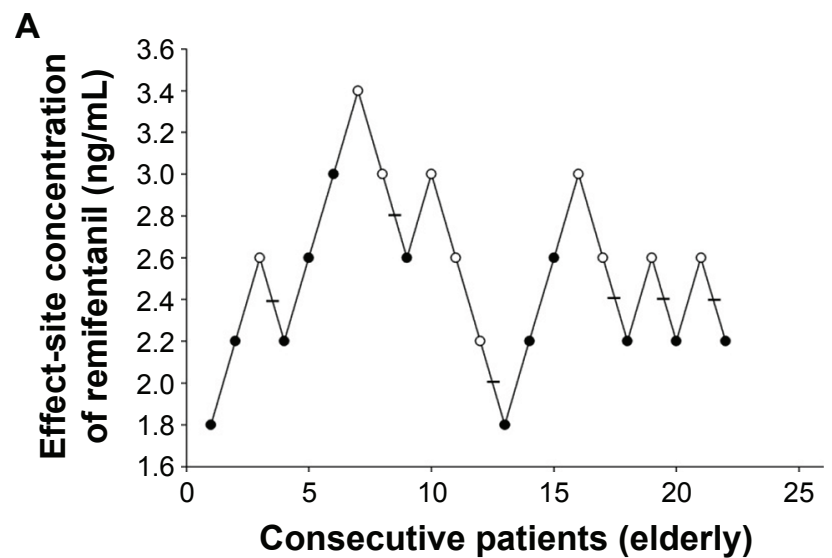

were similar between patient groups, eye opening time (14.1 \pm 3.8 vs $12.0 \pm 2.9$ seconds), extubation time $(17.2 \pm 4.1$ vs $14.0 \pm 3.0$ seconds), and PACU duration (44.5 \pm 7.6 vs $38.7 \pm 3.4$ minutes) in the elderly group were significantly longer than those in the adult group (all $P<0.05$ ). There were no significant differences in pain score and additional analgesic requirement in the PACU between groups.

There were no significant differences in hemodynamic data between elderly and adult patient groups (data not shown). In the present study, the highest concentration of remifentanil used was $3.4 \mathrm{ng} / \mathrm{mL}$ and the lowest concentration was $1.8 \mathrm{ng} / \mathrm{mL}$. Hypoventilation ( $<8$ breaths/min, respiratory rate) occurred in 8/22 (36\%) patients in the elderly group and $6 / 25(24 \%)$ patients in the adult group. Oxygen desaturation $\left(\mathrm{SaO}_{2}<95 \%\right)$ occurred in one patient in the elderly group, but did not occur in the adult patient group. While these adverse events occurred more frequently in the elderly group, there were no significant intergroup differences.

\section{Discussion}

Our results showed that maintaining remifentanil during emergence was an effective method for smooth emergence and the required effect-site concentration of remifentanil in elderly patients was not different from that of the adult patients.

Previous studies have investigated the EC50 and EC95 of remifentanil TCI for cough prevention in various surgeries. ${ }^{8,9}$ Choi et $\mathrm{al}^{8}$ reported the EC50 and EC95 of remifentanil at 2.17 and $2.94 \mathrm{ng} / \mathrm{mL}$, respectively, in males aged 18-60 years (median age 35 years) undergoing nasal surgery after balanced anesthesia with sevoflurane. These results are comparable to the present findings. Our study demonstrated that the EC50 of remifentanil in adult and

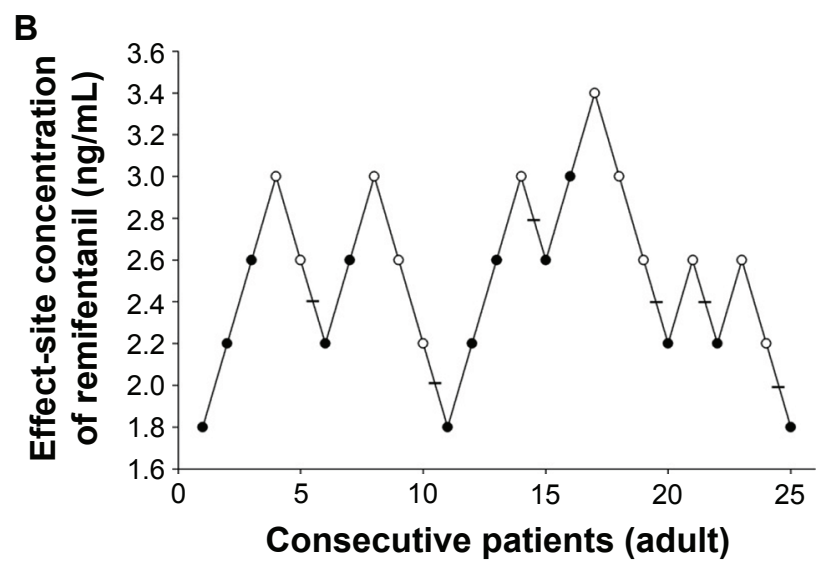

Failure o Success - Mean of pair

Figure 2 Sequences of effect-site concentration of remifentanil for preventing cough during emergence.

Notes: Horizontal bars represent crossover midpoints (ie, success to failure). The effective effect-site concentration for $50 \%$ of patients (EC50) of remifentanil in the (A) elderly and (B) adult patient groups was $2.40 \pm 0.25$ and $2.33 \pm 0.30 \mathrm{ng} / \mathrm{mL}$, respectively. 
Table 2 Recovery profiles

\begin{tabular}{llll}
\hline Variables & $\begin{array}{l}\text { Elderly patients } \\
(\mathbf{n}=\mathbf{2 2})\end{array}$ & $\begin{array}{l}\text { Adult patients } \\
(\mathbf{n}=\mathbf{2 5})\end{array}$ & P-value \\
\hline Operation time (min) & $34.1 \pm I I .5$ & $35.2 \pm I 4.8$ & 0.777 \\
Anesthesia time (min) & $70.4 \pm I 2 . I$ & $7 I .9 \pm 17 . I$ & 0.733 \\
Eye opening (min) & $\mid 4.1 \pm 3.8$ & $12.0 \pm 2.9$ & 0.035 \\
Extubation time (min) & $\mid 7.2 \pm 4 . I$ & $14.0 \pm 3.0$ & 0.004 \\
PACU stay (min) & $44.5 \pm 7.6$ & $38.7 \pm 3.4$ & 0.002 \\
Pain at PACU (NRS) & $3(3-4)$ & $3(3-4.25)$ & 0.302 \\
Additional analgesics & 4 & 4 & 0.835 \\
$\mathrm{SaO}_{2}<95 \%$ & $\mathrm{I}$ & 0 & 0.468 \\
$\mathrm{RR}<8$ breaths/min & $8(36 \%)$ & $6(24 \%)$ & 0.355 \\
\hline
\end{tabular}

Note: Values are expressed as mean \pm standard deviation, median (interquartile range), or number of patients (\%).

Abbreviations: NRS, numerical rating scale; PACU, postanesthetic care unit; $\mathrm{RR}$, respiratory rate; $\mathrm{SaO}_{2}$, oxygen saturation; min, minutes.

elderly patients was 2.33 and $2.40 \mathrm{ng} / \mathrm{mL}$, respectively, without significant intergroup differences. In another study, ${ }^{9}$ the EC95 of remifentanil TCI was $2.51 \mathrm{ng} / \mathrm{mL}$ in patients (aged 20-65 years; mean: 43 years) undergoing transsphenoidal surgery during propofol and remifentanil anesthesia, using biased coin up-and-down sequential allocation and the isotonic regression method.

The effect of aging on cough reflex remains controversial. ${ }^{13,19,20}$ A previous study demonstrated that the sensitivity of cough reflex significantly decreased in the elderly patients compared with that in the young patients, ${ }^{13}$ whereas other studies failed to detect this association. ${ }^{19,20}$ The aging process may also alter pharmacokinetics and pharmacodynamics, ${ }^{11,12}$ and can affect clinical responses to drugs. In general, the elderly are expected to be more sensitive to many drugs, especially opioids. Sensitivity to remifentanil has been reported to be high in elderly patients. ${ }^{14,21}$ The TCI of remifentanil is age variable-adjusted because Minto's model was based on the electroencephalogram (EEG) effect of remifentanil using a three-compartment model with height, weight, and age as covariates. ${ }^{14}$

The present study demonstrated that there was no agerelated difference in the effect-site concentration of remifentanil for cough suppression during emergence. This suggests that remifentanil TCI using Minto's model is appropriate to predict the clinical performance on cough suppression; therefore, there is no need to reduce the effect-site concentration of remifentanil in the elderly. The antitussive effect of narcotics appears to be via opioid receptors such as $\mu$ - and $\kappa$-receptors ${ }^{22,23}$ and, at the subtype level, the antitussive effect of $\mu$-receptors is depressed via $\mu_{2}$-receptors. ${ }^{24}$ However, the opioid receptors involved in the EEG effect in Minto's model may be different from those involved with antitussive action. Therefore, the explanation for the good clinical performance is unclear.
In contrast, recovery profiles such as eye opening time, extubation time, and PACU duration differed between elderly and adult patients in the present study. Although the clinical significance of the prolongation of recovery in the elderly group was relatively minor, it should be treated with caution to some extent. This difference between the elderly and adult patients may be due to several reasons. First, the reduced predictive clinical performance of Minto's model of remifentanil TCI on recovery profiles. As mentioned earlier, Minto's model is based on the EEG effect of remifentanil; ${ }^{14}$ therefore, the influence of age on other clinical variables such as respiration and analgesia may be different. Second, the interpatient variability of remifentanil was larger in the elderly patient group than in the adult group. ${ }^{14}$ Third, sevoflurane may have affected the results because the elimination rate of sevoflurane can be influenced by variations in the respiratory effect of remifentanil according to age or because the minimal alveolar concentration of sevoflurane for awakening also decreases with age. ${ }^{25}$ Therefore, further studies are required to establish a definite conclusion on the influence of age on the clinical performance of remifentanil TCI with regard to recovery profiles.

Hypoventilation $<8$ breaths/min occurred in one-third of patients and desaturation below $95 \%$ in one patient in the elderly group. These adverse events were more frequent in the elderly group, although this difference lacked statistical significance. Remifentanil produces respiratory depression in a dose-dependent manner. ${ }^{26}$ Chang et $\mathrm{al}^{27}$ demonstrated that $2 \mathrm{ng} / \mathrm{mL}$ remifentanil is associated with a significant increase in hypoventilation episodes and delayed emergence. The EC95 of remifentanil for cough suppression during emergence would be more susceptible to respiratory depression. Therefore, when a remifentanil EC95 is administered, caution is required with regard to potential hypoventilation and desaturation.

This study has a few limitations. First, patient sex differences at the enrollment stage were not accounted for; the proportion of males in this study was $72 \%$. According to the results of Soh et al, ${ }^{28}$ the effect-site concentration of remifentanil TCI for antitussive effect is higher in males than in females. Therefore, variations in the dose-response according to sex may have affected this sequential data. Second, the type of surgery was limited to nasal surgery (endoscopic sinus surgery or septoplasty). Based on the differences in the effect-site concentration of remifentanil in previous studies of a similar design, ${ }^{10,27}$ surgery type is likely to influence the effect-site concentration of remifentanil. Therefore, the application of the current findings to other types of surgery should be considered carefully. 


\section{Conclusion}

The effect-site concentration of remifentanil for preventing cough after nasal surgery (endoscopic sinus surgery or septoplasty) with sevoflurane anesthesia in elderly patients did not differ from that in adult patients. However, delayed awakening and respiratory adverse events may warrant special attention in elderly patients.

\section{Disclosure}

The authors report no conflicts of interest in this work.

\section{References}

1. Irwin RS, Ownbey R, Cagle PT, Baker S, Fraire AE. Interpreting the histopathology of chronic cough: a prospective, controlled, comparative study. Chest. 2006;130(2):362-370.

2. Jackson CF, Wenger NK. Cardiovascular disease in the elderly. Rev Esp Cardiol. 2011;64(8):697-712.

3. Lloyd-Jones D, Adams R, Carnethon M, et al. Heart disease and stroke statistics - 2009 update: a report from the American Heart Association Statistics Committee and Stroke Statistics Subcommittee. Circulation. 2009;119(3):e21-e181.

4. Egan TD. Remifentanil pharmacokinetics and pharmacodynamics. A preliminary appraisal. Clin Pharmacokinet. 1995;29(2):80-94.

5. Glass PS, Gan TJ, Howell S. A review of the pharmacokinetics and pharmacodynamics of remifentanil. Anesth Analg. 1999;89(4 Suppl): S7-S14.

6. Aouad MT, Al-Alami AA, Nasr VG, Souki FG, Zbeidy RA, SiddikSayyid SM. The effect of low-dose remifentanil on responses to the endotracheal tube during emergence from general anesthesia. Anesth Analg. 2009;108(4):1157-1160.

7. Nho JS, Lee SY, Kang JM, et al. Effects of maintaining a remifentanil infusion on the recovery profiles during emergence from anaesthesia and tracheal extubation. Br J Anaesth. 2009;103(6):817-821.

8. Choi EM, Park WK, Choi SH, Soh S, Lee JR. Smooth emergence in men undergoing nasal surgery: the effect site concentration of remifentanil for preventing cough after sevoflurane-balanced anaesthesia. Acta Anaesthesiol Scand. 2012;56(4):498-503.

9. Choi SH, Min KT, Lee JR, et al. Determination of EC95 of remifentanil for smooth emergence from propofol anesthesia in patients undergoing transsphenoidal surgery. $J$ Neurosurg Anesthesiol. 2015;27(2): 160-166.

10. Lee B, Lee JR, Na S. Targeting smooth emergence: the effect site concentration of remifentanil for preventing cough during emergence during propofol-remifentanil anaesthesia for thyroid surgery. $\mathrm{Br} J$ Anaesth. 2009;102(6):775-778.
11. Rivera R, Antognini JF. Perioperative drug therapy in elderly patients. Anesthesiology. 2009;110(5):1176-1181.

12. Shafer SL. The pharmacology of anesthetic drugs in elderly patients. Anesthesiol Clin North America. 2000;18(1):1-29.

13. Newnham DM, Hamilton SJ. Sensitivity of the cough reflex in young and elderly subjects. Age Ageing. 1997;26(3):185-188.

14. Minto CF, Schnider TW, Shafer SL. Pharmacokinetics and pharmacodynamics of remifentanil. II. Model application. Anesthesiology. 1997; 86(1):24-33.

15. Aldrete JA. The post-anesthesia recovery score revisited. J Clin Anesth. 1995;7(1):89-91.

16. Dixon WJ. Staircase bioassay: the up-and-down method. Neurosci Biobehav Rev. 1991;15(1):47-50.

17. Paul M, Fisher DM. Are estimates of MAC reliable? Anesthesiology. 2001;95(6):1362-1370.

18. Pace NL, Stylianou MP. Advances in and limitations of up-and-down methodology: a précis of clinical use, study design, and dose estimation in anesthesia research. Anesthesiology. 2007;107(1):144-152.

19. Ebihara S, Ebihara T, Kanezaki M, et al. Aging deteriorated perception of urge-to-cough without changing cough reflex threshold to citric acid in female never-smokers. Cough. 2011;7(1):3.

20. Katsumata U, Sekizawa K, Ebihara T, Sasaki H. Aging effects on cough reflex. Chest. 1995;107(1):290-291.

21. Minto CF, Schnider TW, Egan TD, et al. Influence of age and gender on the pharmacokinetics and pharmacodynamics of remifentanil. I. Model development. Anesthesiology. 1997;86(1):10-23.

22. Kamei J, Tanihara H, Kasuya Y. Antitussive effects of two specific kappa-opioid agonists, U-50,488H and U-62,066E, in rats. Eur $J$ Pharmacol. 1990;187(2):281-286.

23. Kamei J, Tanihara H, Kasuya Y. Modulation of mu-mediated antitussive activity in rats by a delta agonist. Eur J Pharmacol. 1991; 203(1):153-156.

24. Kamei J, Saitoh A, Morita K, Nagase H. Antagonistic effect of buprenorphine on the antitussive effect of morphine is mediated via the activation of mu 1-opioid receptors. Life Sci. 1995;57(16):PL231-PL235.

25. Katoh T, Suguro Y, Kimura T, Ikeda K. Cerebral awakening concentration of sevoflurane and isoflurane predicted during slow and fast alveolar washout. Anesth Analg. 1993;77(5):1012-1017.

26. Mitsis GD, Governo RJ, Rogers R, Pattinson KT. The effect of remifentanil on respiratory variability, evaluated with dynamic modeling. $J \mathrm{Appl}$ Physiol. 2009;106(4):1038-1049.

27. Chang CH, Lee JW, Choi JR, Shim YH. Effect-site concentration of remifentanil to prevent cough after laryngomicrosurgery. Laryngoscope. 2013;123(12):3105-3109.

28. Soh S, Park WK, Kang SW, Lee BR, Lee JR. Sex differences in remifentanil requirements for preventing cough during anesthetic emergence. Yonsei Med J. 2014;55(3):807-814.
Clinical Interventions in Aging

\section{Publish your work in this journal}

Clinical Interventions in Aging is an international, peer-reviewed journal focusing on evidence-based reports on the value or lack thereof of treatments intended to prevent or delay the onset of maladaptive correlates of aging in human beings. This journal is indexed on PubMed Central, MedLine,
Dovepress

CAS, Scopus and the Elsevier Bibliographic databases. The manuscript management system is completely online and includes a very quick and fair peer-review system, which is all easy to use. Visit http://www.dovepress. com/testimonials.php to read real quotes from published authors. 